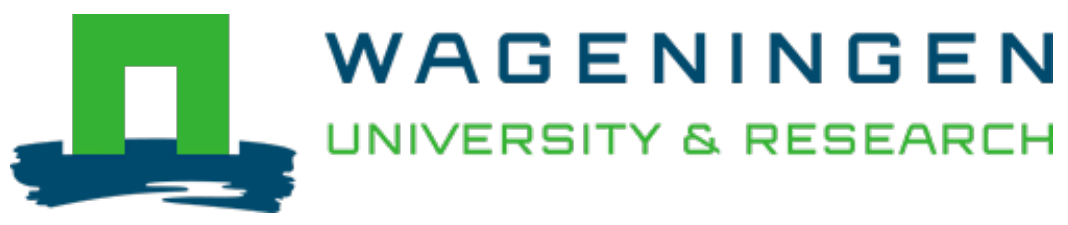

\title{
Limitations of trait-based approaches for stressor assessment: The case of freshwater invertebrates and climate drivers
}

\author{
Global Change Biology \\ Hamilton, Anna T.; Schäfer, Ralf B.; Pyne, Matthew I.; Chessman, Bruce; Kakouei, Karan et al \\ https://doi.org/10.1111/gcb.14846
}

This publication is made publicly available in the institutional repository of Wageningen University and Research, under the terms of article $25 \mathrm{fa}$ of the Dutch Copyright Act, also known as the Amendment Taverne. This has been done with explicit consent by the author.

Article 25 fa states that the author of a short scientific work funded either wholly or partially by Dutch public funds is entitled to make that work publicly available for no consideration following a reasonable period of time after the work was first published, provided that clear reference is made to the source of the first publication of the work.

This publication is distributed under The Association of Universities in the Netherlands (VSNU) 'Article $25 \mathrm{fa}$ implementation' project. In this project research outputs of researchers employed by Dutch Universities that comply with the legal requirements of Article $25 \mathrm{fa}$ of the Dutch Copyright Act are distributed online and free of cost or other barriers in institutional repositories. Research outputs are distributed six months after their first online publication in the original published version and with proper attribution to the source of the original publication.

You are permitted to download and use the publication for personal purposes. All rights remain with the author(s) and / or copyright owner(s) of this work. Any use of the publication or parts of it other than authorised under article $25 \mathrm{fa}$ of the Dutch Copyright act is prohibited. Wageningen University \& Research and the author(s) of this publication shall not be held responsible or liable for any damages resulting from your (re)use of this publication.

For questions regarding the public availability of this publication please contact openscience.library@wur.nl 


\title{
Limitations of trait-based approaches for stressor assessment: The case of freshwater invertebrates and climate drivers
}

\author{
Anna T. Hamilton ${ }^{1}$ (D) | Ralf B. Schäfer ${ }^{2}$ (D) | Matthew I. Pyne ${ }^{3}$ | Bruce Chessman ${ }^{4}$ | \\ Karan Kakouei $^{5}$ (D) | Kate S. Boersma ${ }^{6}$ | Piet F. M. Verdonschot ${ }^{7,8}$ | Ralf C. \\ M. Verdonschot ${ }^{7}$ | Meryl Mims ${ }^{9}$ | Kieran Khamis ${ }^{10}$ | Britta Bierwagen ${ }^{11}$ | Jen Stamp ${ }^{12}$ \\ ${ }^{1}$ Tetra Tech Center for Ecological Sciences, Santa Fe, NM, USA \\ ${ }^{2} \mathrm{iES}$ Landau, Institute for Environmental Sciences, University Koblenz-Landau, Landau, Germany \\ ${ }^{3}$ Department of Biology, Lamar University, Beaumont, TX, USA \\ ${ }^{4}$ Centre for Ecosystem Science, School of Biological, Earth and Environmental Sciences, UNSW Sydney, Sydney, NSW, Australia \\ ${ }^{5}$ Department of Ecosystem Research, Leibniz-Institute of Freshwater Ecology and Inland Fisheries, Berlin, Germany \\ ${ }^{6}$ Department of Biology, University of San Diego, San Diego, CA, USA \\ ${ }^{7}$ Wageningen Environmental Research, Wageningen University and Research, Wageningen, The Netherlands \\ ${ }^{8}$ Institute for Biodiversity and Ecosystem Dynamics, University of Amsterdam, Amsterdam, The Netherlands \\ ${ }^{9}$ Department of Biological Sciences, Virginia Tech, Blacksburg, VA, USA \\ ${ }^{10}$ School of Geography, Earth and Environmental Sciences, University of Birmingham, Birmingham, UK \\ ${ }^{11}$ Office of Research and Development, National Center for Environmental Assessment, U.S. Environmental Protection Agency, Washington, DC, USA \\ ${ }^{12}$ Tetra Tech Center for Ecological Sciences, Montpelier, VT, USA
}

\section{Correspondence}

Anna T. Hamilton, Tetra Tech Center for Ecological Sciences, Santa Fe, NM, USA. Email: Anna.Hamilton@tetratech.com

\section{Funding information}

Deutsche Forschungsgemeinschaft, Grant/Award Number: SCHA 1720/18-1; BiodivERsA, Grant/Award Number: AD 91/22-1; Belmont Forum; U.S. Environmental Protection Agency, Grant/ Award Number: EP-C-17-031 TO 002 and EP-C-12-060 WA 4-01

\begin{abstract}
The appeal of trait-based approaches for assessing environmental vulnerabilities arises from the potential insight they provide into the mechanisms underlying the changes in populations and community structure. Traits can provide ecologically based explanations for observed responses to environmental changes, along with predictive power gained by developing relationships between traits and environmental variables. Despite these potential benefits, questions remain regarding the utility and limitations of these approaches, which we explore focusing on the following questions: (a) How reliable are predictions of biotic responses to changing conditions based on single trait-environment relationships? (b) What factors constrain detection of single trait-environment relationships, and how can they be addressed? (c) Can we use information on meta-community processes to reveal conditions when assumptions underlying trait-based studies are not met? We address these questions by reviewing published literature on aquatic invertebrate communities from stream ecosystems. Our findings help to define factors that influence the successful application of trait-based approaches in addressing the complex, multifaceted effects of changing climate conditions on hydrologic and thermal regimes in stream ecosystems. Key conclusions are that observed relationships between traits and environmental stressors are often inconsistent with predefined hypotheses derived from current trait-based
\end{abstract}


thinking, particularly related to single trait-environment relationships. Factors that can influence findings of trait-based assessments include intercorrelations of among traits and among environmental variables, spatial scale, strength of biotic interactions, intensity of habitat disturbance, degree of abiotic stress, and methods of trait characterization. Several recommendations are made for practice and further study to address these concerns, including using phylogenetic relatedness to address intercorrelation. With proper consideration of these issues, trait-based assessment of organismal vulnerability to environmental changes can become a useful tool to conserve threatened populations into the future.

\section{KEYWORDS}

bioassessment, climate stressor responses, freshwater invertebrates, invertebrate traits, stressor assessment, trait-based assessment

\section{1 | INTRODUCTION}

Ecosystems are subject to multiple anthropogenic stressors such as habitat degradation, excessive inputs of nutrients and toxicants, and changing climatic conditions (Goudie, 2018; MEA, 2005; Vörösmarty et al., 2010), including altered air temperature and precipitation patterns and increased frequency and intensity of extreme weather events (Wuebbles et al., 2017). Understanding the effects of these stressors on biotic populations and communities, including the estimation of vulnerability or resilience to these stressors, is crucial for ecosystem management. Trait-based assessment is an alternative to taxonomically based characterization of communities and a promising and increasingly utilized tool for environmental assessment (e.g., Chessman, 2015; Foden et al., 2013; Griswold, Berzinis, Crisman, \& Golladay, 2008). However, the application of trait-based approaches has still not achieved its full potential, due in part to methodological inconsistencies and challenges in interpreting the results from different study designs.

Organism traits include morphological, physiological, and behavioral features operating at the level of the individual, as well as some population characteristics such as the number of generations per year (voltinism). As determinants of functions, individual traits can reveal the mechanisms that drive the patterns of organism distribution and abundance (McGill, Enquist, Weiher, \& Westoby, 2006;
Winemiller, Fitzgerald, Bower, \& Pianka, 2015). Traits therefore offer a basis for establishing and testing mechanistic hypotheses about organism-stressor (including climate variables) relationships in natural populations (Figure 1). Both trait- and taxonomy-based studies involve tracking population and community changes and relating them to environmental factors; the key difference is the potential to use traits as a diagnostic tool coupled with the expectation that trait responses can be generalized across biogeographic regions and time (e.g., Brown, Khamis, et al., 2017), and potentially predicted into the future (Webb, Hoeting, Ames, Pyne, \& Poff, 2010).

Despite the potential benefits of using assessments based on a single trait or a small subset of traits to predict the responses of biotic populations to a changing climate and associated impacts on communities, questions remain regarding the utility and limitations of this approach. We identify and address the following questions:

1. How reliable are predictions of biotic responses to changing conditions based on individual traits and environmental variables?

2. What factors constrain detection of single trait-environment relationships, and how can they be addressed?

3. Can we use information on meta-community processes to reveal conditions when assumptions underlying trait-based studies are not met?

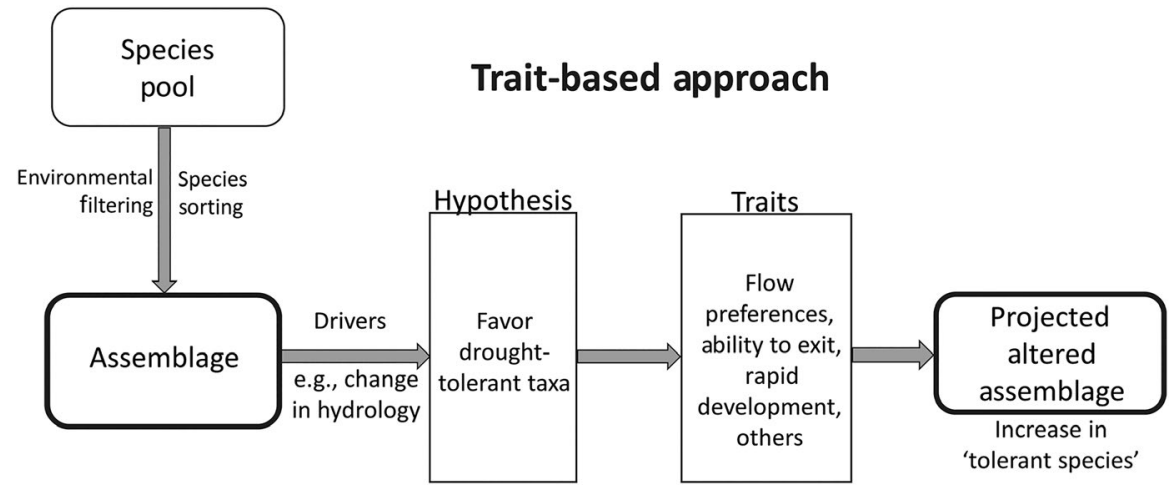

FIGURE 1 Example of a trait-based hypothesis regarding changes in stream invertebrate assemblages due to a changing climate 
Answers to these questions are likely to affect the design and interpretation of trait-based studies, and we address them by reviewing published literature on aquatic invertebrate communities in stream ecosystems. Our findings help to define success factors for trait-based exploration of the complex, multifaceted effects of a changing climate on stream ecosystems via hydrologic and thermal regimes, recognizing that these regimes are also influenced by non-climatic factors such as water management and land use.

\section{I HOW RELIABLE ARE SINGLE TRAIT-BASED PREDICTIONS?}

Early trait-based approaches commonly examined the relationship of a single trait to a single environmental variable (often referred to in the literature as a 'univariate' relationship; Cummins et al., 1980; Fahy, 1975; Hawkins, Murphy, \& Anderson, 1982; Townsend, Hildrew, \& Francis, 1983), using ecological (Domisch et al., 2013; Hamilton, Stamp, \& Bierwagen, 2010), biological (Chessman, 2015; Lange, Townsend, \& Matthaei, 2014), or life-history (Bonada, Dolédec, \& Statzner, 2007; Chevalier, Comte, Laffaille, \& Grenouillet, 2018) traits. Even though an early example (Usseglio-Polatera \& Tachet, 1994) evaluated multiple traits using multivariate analysis, the discussion and interpretation of results was still done trait by trait (i.e., univariate). Single-trait analyses are useful because the relationships between individual traits and single-variable environmental gradients are easy to conceptualize, and associated hypotheses are simple to test. As a result, examples of predicted relationships between environmental variables and single traits are abundant in the ecological literature (e.g., Allan \& Castillo, 2007; Giller \& Malmqvist, 1998; Hynes, 1970).

\section{1 | Relationships between trait predictions and climate}

To explore whether predicted trait-climate relationships are realized, we reviewed 11 commonly cited papers on such relationships for stream macroinvertebrates (Table 1) to compare their findings to a priori, ecologically based predictions. An example of an a priori prediction (i.e., a hypothesized relationship between a trait and an environmental variable based on the perceived functional characteristic of the trait) is that cold-adapted stenothermic macroinvertebrates will be vulnerable to increasing stream temperatures near the lower margins of their elevational ranges where temperatures already approach their upper thermal tolerances (Hering et al., 2009; Stamp, Hamilton, Zheng, \& Bierwagen, 2010). Eleven ecological or life-history traits were examined across the 11 studies, and 34 of 61 relationships between trait states and climate variables (56\%) fulfilled predictions. Only two of the 11 traits (preferences for water current and temperature preferences) were associated with climate signals in every study where they were tested. These findings suggest that a few single traitclimate variable relationships are quite consistent, although even in these cases, trait-state assignments that are inconsistent with actual environmental preferences (e.g., rheophily) can obscure relationships (Herbst, Cooper, Medhurst, Wiseman, \& Hunsaker, 2018). Moreover, we found a surprising level of incongruence between a priori predictions and species responses to climate signals, suggesting that a single trait-environment relationship may vary considerably according to the context of the study and other factors extrinsic (e.g., interactions among environmental variables) or intrinsic (e.g., related to physiology, age or life stage) to the organism.

To determine the consistency of predicted single trait-environment relationships across multiple studies, we surveyed trait relationships with two stream characteristics related to the changes in precipitation patterns: (a) flow intensity and (b) the occurrence of low flows or drought. The stream ecology literature describes evolutionary adaptations to specific stream environmental conditions, such as flow, which allowed us to make trait-environment predictions.

\section{2 | Relationships with flow intensity}

We extracted 52 a priori predictions from 42 stream ecology publications that theoretically linked various traits and at least one measure of flow intensity (e.g., runoff, velocity, and shear stress; Table S1). For example, McCafferty (1998) hypothesized that increasing flows reduce the distribution and abundance of organisms that burrow or climb, but increase the distribution and abundance of those that cling to substrata. We consolidated these hypotheses into 28 predictions related to the changes in flow intensity (Table 2).

We then compared these predictions to the trait-environment relationships reported in 67 papers (listed in Table S2). About 270 relationships between flow variables and 14 traits were tested in these studies (Table 2), of which 157 (58\%) were statistically non-significant (according to the original authors), 80 (30\%) matched a priori predictions, and 33 (12\%) contradicted a priori predictions.

\section{3 | Relationships with low-flow magnitude}

We extracted 65 a priori predictions from 42 stream ecology publications that theoretically linked various traits and at least one measure of extremely low flows (e.g., intermittency, drought, and desiccation periodicity or duration; Table S1). For example, Ward (1992) suggested that environments prone to intermittency favor air-breathing macroinvertebrates, since they are resistant to the depletion of dissolved oxygen within the stream during low-flow periods. We consolidated these predictions into 15 relating to loss of flow or intermittency (Table 3).

From the trait-environment relationships reported in the $67 \mathrm{pa}-$ pers (Table S2), 214 relationships between intermittency/drought variables and seven traits were tested (Table 3). Of these, 133 (62\%) found no relationship, 44 (21\%) matched a priori predictions, and 37 (17\%) contradicted a priori predictions.

Thus, most predicted single-trait responses were not realized or were contradicted. In some cases, inconsistency among 
TAB LE 1 Overview of responses of traits ( $+=$ response, $0=$ no response, NA = not assessed) to climate extremes and long-term climatic stressors in freshwater ecosystems in previous studies. Note that the criteria used to evaluate the responses of traits to climate variables varied across studies and could not be harmonized without access to the raw data

\begin{tabular}{|c|c|c|c|c|c|}
\hline Study & Chessman (2015) & Griswold et al. (2008) & Walters (2011) & $\begin{array}{l}\text { Woodward, Bonada, } \\
\text { Feeley, and Giller } \\
\text { (2015) }\end{array}$ & Lawrence et al. (2010) \\
\hline Study type & $\begin{array}{l}\text { Extreme event } \\
\text { (cessation of } \\
\text { drought) }\end{array}$ & $\begin{array}{l}\text { Extreme event } \\
\text { (cessation of drought) }\end{array}$ & $\begin{array}{l}\text { Extreme event } \\
\text { (comparison of } \\
\text { drought to control) }\end{array}$ & $\begin{array}{l}\text { Extreme event } \\
\text { (multiple events) }\end{array}$ & $\begin{array}{l}\text { Long-term trends } \\
\text { (20 years) }\end{array}$ \\
\hline $\begin{array}{l}\text { Criteria to evaluate the } \\
\text { response of trait to } \\
\text { climate variable }\end{array}$ & $\begin{array}{l}\text { Spearman } \\
\rho>0.25 \text { with } \\
\text { drought indices }\end{array}$ & $\begin{array}{l}\text { Pearson } r>.6 \\
\text { with ordination axes } \\
\text { related to climatic } \\
\text { variables }\end{array}$ & $\begin{array}{l}p<.1 \text { for effect of } \\
\text { water diversion } \\
\text { (high } p \text { because of } \\
n=6 \text { ) }\end{array}$ & $\begin{array}{l}p<.05 \text { for effect of } \\
\text { extreme event }\end{array}$ & $\begin{array}{l}>25 \% \text { change in } \\
\text { community trait } \\
\text { composition between } \\
\text { years }\end{array}$ \\
\hline Scale & $\begin{array}{l}\text { Regional ( 800 } \\
\text { stream sites) }\end{array}$ & Local (two sites) & $\begin{array}{l}\text { Local (three stream } \\
\text { sites) }\end{array}$ & Local (one site) & Local (four sites) \\
\hline $\begin{array}{l}\text { Temperature } \\
\text { preference }\end{array}$ & + & NA & NA & NA & NA \\
\hline Reproductive capacity & NA & + & NA & 0 & 0 \\
\hline Reproduction type & NA & NA & NA & NA & NA \\
\hline Life cycle duration & 0 & NA & NA & 0 & NA \\
\hline Body size & 0 & 0 & 0 & + & 0 \\
\hline Feeding type & 0 & + & 0 & + & NA \\
\hline Respiration mode & 0 & NA & NA & + & NA \\
\hline Dispersal capacity & NA & 0 & + & + & NA \\
\hline
\end{tabular}

the studies could be due to the methodological factors, such as low study power or conflicting trait values. For example, Herbst et al. (2018) found that assignment to rheophily categories differed between two widely used sources (Merritt, Cummins, \& Berg, 2008; Poff et al., 2006) for many taxa, and that about half of empirically derived rheophily associations differed from each of these sources. Also, the length of the environmental gradient, even for strong environmental drivers such as temperature and flow, may affect the degree of environmental filtering observed. Other factors, such as trait plasticity, trait intercorrelations (e.g., linkage of tested traits to other traits responding to different environmental variables), multiple correlated environmental variables, poor establishment of a priori hypotheses founded in ecological principles, or trait responses that might vary in time, could further confound or mask single trait-environment relationships. A more refined ability to account for such factors is needed before we can trust our interpretations of single trait-based responses and predictions with respect to climatic variables; and some of these factors are considered below.

\section{I WHAT FACTORS POTENTIALLY CONSTRAIN SINGLE-TRAIT RELATIONSHIPS?}

Organisms respond to environmental conditions according to their trait values in a process called environmental filtering (Poff, 1997; Tonn, 1990) or environmental selection (Vellend, 2010; Figure 2). Kraft et al. (2015) define environmental filtering as the control of species establishment and persistence by abiotic variables, which they separate from the role of biotic interactions such as competitive exclusion. An assumption that abiotic environmental filtering is dominant underpins most trait-based assessments, but the strength of the environmental factor being considered (i.e., the degree of environmental stress) may be important in determining how much filtering occurs. In addition, environmental factors do not operate independently in structuring communities, and both abiotic and biotic factors may operate as filters at multiple, potentially nested scales (Poff, 1997; Tonn, 1990; Figure 2). If biotic interactions exert a strong influence over the distribution 


\begin{tabular}{|c|c|c|c|c|c|}
\hline Chessman (2012) & Stamp et al. (2010) & Bêche and Resh (2007) & Bonada et al. (2007) & $\begin{array}{l}\text { Poff, Pyne, Bledsoe, } \\
\text { Cuhaciyan, and } \\
\text { Carlisle (2010) }\end{array}$ & $\begin{array}{l}\text { Bhowmik and } \\
\text { Schäfer (2015) }\end{array}$ \\
\hline $\begin{array}{l}\text { Long-term trends } \\
\text { (16 years) }\end{array}$ & $\begin{array}{l}\text { Long-term trends } \\
\text { (9-22 years) }\end{array}$ & $\begin{array}{l}\text { Long-term trends } \\
\text { (7-20 years) }\end{array}$ & Space-for-time & Space-for-time & Space-for-time \\
\hline $\begin{array}{c}\text { Pearson } r>.6 \text { with } \\
\text { climatic variables }\end{array}$ & $\begin{array}{c}\text { Pearson } r>.6 \text { with } \\
\text { climatic variables }\end{array}$ & $\begin{array}{l}\text { Traits associated with } \\
\text { ordination axes related } \\
\text { to climatic variables }\end{array}$ & $\begin{array}{l}>25 \% \text { change in } \\
\text { community trait } \\
\text { composition } \\
\text { between regions }\end{array}$ & $\begin{array}{l}>25 \% \text { change in } \\
\text { community trait } \\
\text { composition } \\
\text { between regions }\end{array}$ & $\begin{array}{l}>35 \% \text { explained } \\
\text { variance by } \\
\text { bioclimatic } \\
\text { variables }\end{array}$ \\
\hline $\begin{array}{l}\text { Regional ( 9,000 } \\
\text { samples) }\end{array}$ & Regional (eight sites) & Local (four sites) & Large scale (530 sites) & Large scale (279 sites) & $\begin{array}{l}\text { Large scale }(4,752 \\
\text { sites) }\end{array}$ \\
\hline+ & + & NA & NA & + & + \\
\hline NA & NA & + & 0 & + & 0 \\
\hline NA & NA & + & 0 & NA & NA \\
\hline NA & NA & + & 0 & NA & NA \\
\hline NA & NA & + & 0 & NA & 0 \\
\hline NA & NA & + & 0 & NA & NA \\
\hline NA & NA & + & 0 & NA & NA \\
\hline NA & NA & + & 0 & + & 0 \\
\hline
\end{tabular}

and abundance of taxa at the local level, independently of abiotic variables, the expected relationship between a trait and an abiotic variable might be confounded or masked. Thus, a strong influence from biotic filtering has the potential to impair our ability to test trait-abiotic variable relationships using field data.

Several other factors pose challenges for single-trait assessments, including trait non-independence, measurement scales used for assigning trait values (e.g., categorical vs. continuous), plasticity of trait expression, and methods used for trait characterization.

\section{1 | Trait non-independence}

Ecosystems are simultaneously impacted by multiple stressors that collectively act on organisms through multiple traits. More than a decade ago, Poff et al. (2006) highlighted a significant limitation to single-trait approaches: traits are not independent of one another. The lack of independence among traits may lead to misguided or unsubstantiated single-trait predictions, and attention to issues of trait non-independence has recently renewed (de Bello et al., 2017; Verberk, Noordwijk, \& Hildrew, 2013). There are two separate but related issues. Single-trait responses to environmental variables can vary among phylogenetic groups (Pilière et al., 2016; Verberk et al., 2013), and testing single traits may not be testing the same functional adaptation to an environmental gradient in each group (Pilière et al., 2016). Traits may also be correlated because of mechanistic relationships (linked or co-occurring traits). For example, multivoltine species necessarily have rapid development, rapid development is more feasible if adult body size is small (Resh et al., 1988), and negative correlations between voltinism and body size have been recognized (Usseglio-Polatera, Bournaud, Richoux, \& Tachet, 2000; Verberk, Siepel, \& Esselink, 2008). Also, trophic position can be related to body size, which determines the ability to consume particular foods. Traits often occur as trait groups (Pilière et al., 2016; Poff et al., 2006) due to past selection processes that jointly shaped a limited number of life-history strategies or morphological characteristics.

Traits also will not be independent at the species level if they are conserved within higher taxa: a phenomenon that is captured in 
TAB LE 2 Relationships between measures of flow intensity (e.g., increasing flow volume, runoff or water velocity, as metrics of high flow conditions) and trait states

\begin{tabular}{|c|c|c|c|c|c|c|}
\hline Trait & Trait state & $\begin{array}{l}\text { Predicted } \\
\text { relationship }\end{array}$ & \multicolumn{3}{|c|}{ No. of observed relationships } & Total \\
\hline Armoring & No armoring & Negative & 1 & 2 & 0 & 3 \\
\hline Armoring & Poor to good armoring & Positive & 4 & 0 & 2 & 6 \\
\hline Attachment & No attachment & Negative & 2 & 0 & 0 & 2 \\
\hline Attachment & Some level of attachment & Positive & 4 & 1 & 0 & 5 \\
\hline Development & Slow, seasonal development & Negative & 2 & 0 & 0 & 2 \\
\hline Functional Feeding Group & Collector-filterers & Positive & 25 & 21 & 7 & 53 \\
\hline Functional Feeding Group & Collector-gatherer & Negative & 21 & 10 & 19 & 50 \\
\hline Functional Feeding Group & Predator & Negative & 25 & 4 & 15 & 44 \\
\hline Habit & Swimmers & Negative & 7 & 0 & 3 & 10 \\
\hline Occurrence in drift & Abundant or common in drift & Mixed & 3 & 1 & 0 & 4 \\
\hline Occurrence in drift & Rare in drift & Mixed & 1 & 1 & 0 & 2 \\
\hline Respiration & Air respiration & Negative & 3 & 1 & 0 & 4 \\
\hline Respiration & Tegument respiration & Positive & 1 & 1 & 2 & 4 \\
\hline Rheophily & Depositional environment preference & Negative & 6 & 0 & 2 & 8 \\
\hline Rheophily & Erosional environment preference & Positive & 2 & 5 & 1 & 8 \\
\hline Size & Large size & Negative & 3 & 0 & 0 & 3 \\
\hline Size & Medium size & Mixed & 2 & 1 & 0 & 3 \\
\hline Voltinism & Univoltine & Negative & 2 & 0 & 1 & 3 \\
\hline Total & & & 157 & 57 & 56 & 270 \\
\hline
\end{tabular}

Note: The Predicted relationship column shows a priori predictions based on ecological theory, extracted from 42 sources (listed in Table S1). A 'mixed' prediction means that some sources suggested a positive relationship and others indicated a negative relationship (i.e., no consensus). Numbers in the None, Positive(Pos), and Negative (Neg) columns are the numbers of relationships reported in 67 papers (listed in Table S2).

phylogeny. For example, Malaj, Guénard, Schäfer, and Ohe (2016) found that phylogeny explained $>40 \%$ of the variation in tolerance of six heavy metals among invertebrate species. Poff et al. (2006) suggested that 'labile' traits, that is those that are relatively unconstrained by phylogeny, need to be emphasized in assessments, whereas Verberk et al. (2013) stressed the need to consider phylogenetically constrained traits that may have been conserved for ecologically important reasons. This conservatism could lead to taxonomic patterns mirroring trait patterns in some circumstances (e.g., Herbst et al., 2018).

Relationships between a single trait and an environmental gradient can be misleading if co-occurring environmental variables or stressors are not considered (Pyne \& Poff, 2017). Co-occurring environmental variables can be correlated (e.g., stream temperature, flow velocity, and dissolved oxygen concentration) and jointly associated with a trait group or 'syndrome' (Chessman, 2018). Thus, an apparent trait-related response may be associated with more than one environmental variable. As a result, single trait-environment responses may be influenced by other, often unmeasured, environmental variables, or may result from the response of a linked trait, potentially leading to the misattribution of cause.

\section{2 | Categorical traits}

The outcomes of trait assessments may depend on the assignment of trait values, which are typically based on the literature reviews and expert knowledge (Schmidt-Kloiber \& Hering, 2015). 
TAB LE 3 Relationships between measures of intermittency or extreme low flows (i.e., increasing frequency or duration of low flows) and trait states

\begin{tabular}{|c|c|c|c|c|c|c|}
\hline \multirow[b]{2}{*}{ Trait } & \multirow[b]{2}{*}{ Trait state } & \multirow{2}{*}{$\begin{array}{l}\text { Predicted } \\
\text { relationship }\end{array}$} & \multicolumn{4}{|c|}{ No. of observed relationships } \\
\hline & & & None & Pos & Neg & Total \\
\hline Adult life span & Long (>1 month) & Positive & 1 & 0 & 3 & 4 \\
\hline Adult life span & $\begin{array}{r}\text { Very short } \\
\text { (<1 week) }\end{array}$ & Negative & 0 & 2 & 0 & 2 \\
\hline $\begin{array}{l}\text { Desiccation } \\
\text { resistance }\end{array}$ & Present & Positive & 9 & 2 & 2 & 13 \\
\hline $\begin{array}{l}\text { Functional } \\
\text { Feeding Group }\end{array}$ & Collector-Filterer & Negative & 16 & 4 & 8 & 28 \\
\hline $\begin{array}{l}\text { Functional } \\
\text { Feeding Group }\end{array}$ & Collector-gatherer & Positive & 19 & 6 & 8 & 33 \\
\hline $\begin{array}{l}\text { Functional } \\
\text { Feeding Group }\end{array}$ & $\begin{array}{l}\text { Herbivore } \\
\text { (scraper, piercer, } \\
\text { etc) }\end{array}$ & Negative & 15 & 2 & 7 & 24 \\
\hline $\begin{array}{l}\text { Functional } \\
\text { Feeding Group }\end{array}$ & Predator & Positive & 17 & 4 & 11 & 32 \\
\hline Habit (functional) & Burrower & Positive & 4 & 4 & 0 & 8 \\
\hline Habit (functional) & Swimmer & Positive & 13 & 2 & 4 & 19 \\
\hline Respiration & Aerial & Positive & 8 & 2 & 1 & 11 \\
\hline Respiration & Tegument & Negative & 4 & 0 & 1 & 5 \\
\hline Size & Large (>16 mm) & Mixed & 12 & 0 & 3 & 15 \\
\hline Size & Small (<9 mm) & Positive & 11 & 4 & 0 & 15 \\
\hline Voltinism & Multivoltine & Mixed & 2 & 0 & 0 & 2 \\
\hline Voltinism & Semivoltine & Negative & 2 & 0 & 1 & 3 \\
\hline Total & & & 133 & 32 & 49 & 214 \\
\hline
\end{tabular}

Note: The Predicted relationship column shows a priori predictions based on ecological theory, extracted from 42 sources (listed in Table S1). Numbers in the None, Positive (Pos), and Negative (Neg) columns are the numbers of relationships reported in 67 papers (listed in Table S2).
FIGURE 2 Illustration of

environmental filtering (abiotic and biotic) and the related concept of species sorting (defined in the text), which underpin traitbased approaches (adapted from Poff, 1997). Note that the illustration is not intended to suggest that environmental filtering is linear and sequential (abiotic, then biotic); it may be iterative or nested, as indicated by the bidirectional arrows between those two layers

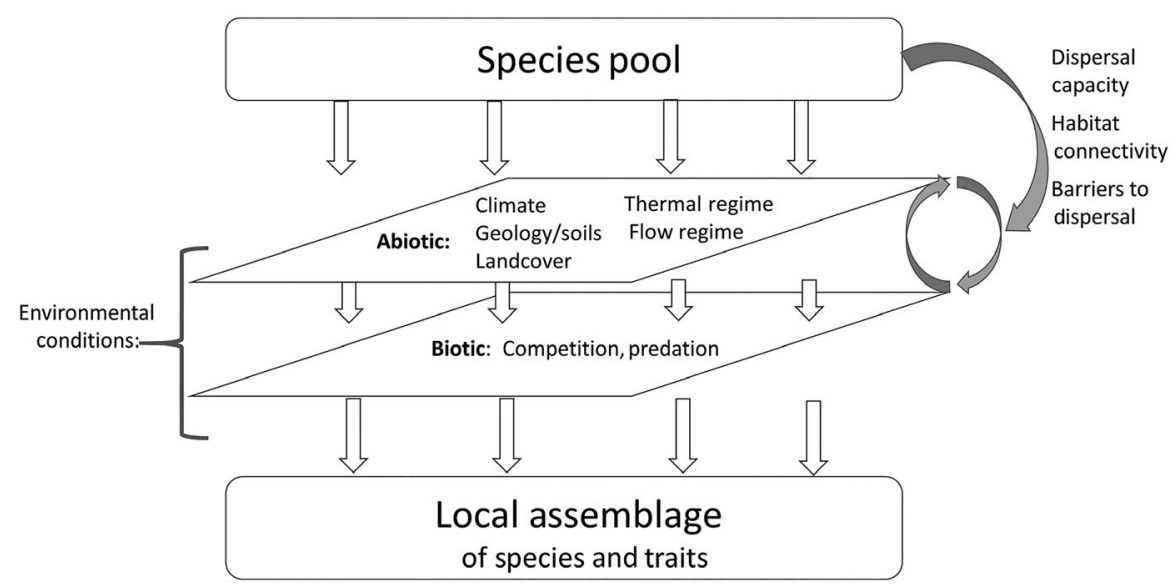

Trait values are usually grouped into a few categories (e.g., feeding type categorized as filterer, gatherer, predator, scraper, or shredder; stream flow preference [rheophily] categorized as erosional or depositional). Assignment of categorical trait values by expert knowledge can be subjective, pointing to the need for quantitative trait studies. For example, recording occurrences in riffles and pools more rigorously could hone the assignment of erosional, depositional, or intermediate preferences to express the trait of rheophily (Herbst et al., 2018). Although it might be an even bigger challenge, inferences could be improved by expressing some traits on continuous rather than categorical scales, using analytical approaches pioneered by Yuan (2006). Progress has been made in using extensive data sets to characterize certain environmental preference or tolerance traits as continuous variables, such as for flow velocity, temperature, and dissolved oxygen (e.g., Chessman, 2018). As such estimates are made for particular regions, environments, and taxa, their transferability may be constrained by regional differences in environmental variability and the taxonomic 
composition of assemblages, particularly if trait values are estimated at higher taxonomic levels. However, comparative analyses across regionalized data sets could allow for the development of harmonized preference or tolerance values. Categorical trait assignments can also offer challenges for assessment in conjunction with continuous quantitative data such as flow or projected flow alterations (Kakouei et al., 2018).

\section{3 | Trait plasticity}

Trait information derived from field observations of the occurrence of taxa can cut across multiple environments, climates, and geographic regions (Schmidt-Kloiber \& Hering, 2015). Species display trait plasticity that can include adaptations to regional conditions, which complicate trait-environmental relationships (Ortega-Mayagoitia, Hernandez-Martinez, \& Ciros-Perez, 2018). As a result, trait values may not be generalizable across geographic areas (Mbaka, Szöcs, \& Schäfer, 2015).

\subsection{Other sources of variability}

Trait-based studies have also suffered from a lack of information, especially at the species level, partly due to incomplete taxonomic information and difficulties in identification of larval insects. For example, dipteran species are often underrepresented in trait databases, although there have been some developments recently for the family Chironomidae (Cañedo, Bogan, Lytle, \& Prat, 2016; Serra, Cobo, Graça, Dolédec, \& Feio, 2016). Traits such as temperature or flow preferences can vary among congeneric species, a factor that should be considered when data being assessed are constrained to genus or higher levels of taxonomic resolution (Pyne \& Poff, 2017).

Even when such sources of variation are minor, ecological traits suffer from interpretation issues linked to typological (i.e., classification) differences among stream systems. For example, in the northwestern European lowlands, rheophily classifications are based on occurrence patterns in sand-bottom, slow-flowing, lowland streams. Species occurring in high flow environments are typically classified as rheophiles, but the definition of 'high flow' may vary by site. When comparing communities from low-gradient rivers with those from high-gradient, gravel-bed, central-European streams, the same species might be classified differently (e.g., different rheophily indices in Schmidt-Kloiber \& Hering, 2015). Efforts to better link stream typologies, which incorporate stream size, to trait databases might result in more accurate trait characterizations on a local scale.

\section{4 | WHAT TO DO ABOUT CONSTRAINING FACTORS?}

The above section outlines some challenges to effective use of traitbased approaches, but there are some approaches that, with further refinement, could minimize problems.

\section{1 | Control for phylogenetic relationships}

Recognizing the intercorrelation of traits among taxa as a product of evolution as well as a limitation on using single traits to track or predict responses to environmental gradients, Poff et al. (2006) termed a taxon's set of trait states as its functional trait niche (FTN), a combination that determines its integrated response to environmental conditions. In their analysis of 20 traits comprising 59 trait states across 311 taxa from 75 families of lotic insects, Poff et al. (2006) derived 233 FTNs, meaning that some taxa had the same FTN for the traits included in the assessment. Increasing the number of traits considered in an FTN analysis would reduce the similarity in FTNs among taxa, making an analysis based on FTNs closer to a comparison among taxa. Thus, to use FTNs as an organizing tool for trait-based assessment, the number of traits included would have to be limited or the defined trait states would have to be broader. Poff et al. (2006) selected the traits that are minimally constrained by evolutionary linkage, that is by phylogeny, and recommended these traits to track and predict responses to environmental gradients. In addition to this conceptual approach, further research elucidating relationships among phylogeny, trait associations, and community ecology (e.g., Tucker et al., 2017; Webb, Ackerly, McPeek, \& Donoghue, 2002) could advance analytical approaches for interpreting trait-based study results and informing designs. Some of these efforts examine relationships between multidimensional trait space and dimensions of phylogenetic relatedness, helping to connect trait assessments with the niche-space concept (Tucker, Davies, Cadotte, $\&$ Pearse, 2018) and the relative influences of abiotic environmental filtering and competitive exclusion (Webb et al., 2002). However, more work is needed to better integrate these advances into traitbased approaches.

Several other methods have been developed to account for phylogenetic relationships in trait-based assessments, and these approaches could increase the efficacy of trait-based vulnerability assessments. New interest in community phylogenetics suggests that relative phylogenetic distances among species can explain ecological differences (Cadotte, Davies, \& Peres-Neto, 2017), and taxonomic groups can be used to partly account for trait linkages via evolutionary history (Pilière et al., 2016). A related approach is to define groups of taxa that share sets of associated trait values using cluster analysis, and then use the resulting Trait Profile Groups as assessment units (Pilière et al., 2016; Usseglio-Polatera, Richoux, Bournaud, \& Tachet, 2001). More recently, a technique for decoupling functional traits from phylogeny has been developed (de Bello et al., 2017), which builds on previous mathematical approaches for weighting trait patterns by phylogenetic signals (Diniz-Filho, Cianciaruso, Rangel, \& Bini, 2011; Pillar \& Duarte, 2010); rather than using a combined dissimilarity in functional traits and phylogeny, it accounts for the overlap between them (covariance).

Other methods, such as phylogenetic eigenvectors maps (Guénard, Legendre, \& Peres-Neto, 2013) have been developed to estimate the trait values from phylogenetic signals. These 
techniques can account for intercorrelation among traits associated with phylogeny to improve the interpretation of trait-based assessment results. They can also reveal when missing trait information can be replaced by phylogenetic information in applied trait studies.

\section{2 | Group by life-history strategies}

Another means of dealing with the lack of independence of individual traits is to group trait combinations according to lifehistory strategies. Life-history strategies have been defined as 'sets of coevolved traits which enable a species to deal with a range of ecological problems' (Verberk et al., 2008). Verberk et al. (2013) suggested the need for greater analytical flexibility when exploring mechanistic relationships between traits and environmental conditions. They developed a framework with four levels-traits, trait interactions, trait combinations, and life-history strategies-and classified life-history strategies of freshwater invertebrates into four trait domains: reproduction, development, dispersal, and synchronization. For freshwater fish, Winemiller and Rose (1992) developed a classification into three strategies: periodic, opportunistic, and equilibrium. Periodic species are characterized by late maturation, large clutch sizes, and high adult survival; opportunistic species are characterized by early maturation, frequent reproduction over a long spawning season, and rapid larval growth; and equilibrium species are characterized by parental care of small clutches of large eggs. Such life-history strategies have been used to establish relationships with environmental conditions. For example, life-history strategies of freshwater fish correlate with flow-regime characteristics and hydraulic preferences (Blanck, Tedesco, \& Lamouroux, 2007; Mims \& Olden, 2012; Olden \& Kennard, 2010; Scharbert \& Borcherding, 2013). Mims and Olden (2013) found that fish assemblages downstream of dams had a higher proportion of equilibrium species and a lower proportion of opportunistic species than those of free-flowing locations. Similarly, McManamay and Frimpong (2015) concluded that equilibrium strategists increase following the flow regulation by dams, whereas opportunistic and periodic species decrease.

Life-history strategies are also likely important in determining relative vulnerability to changes in hydrology and thermal conditions. For example, Chessman (2013) found that fish species with periodic lifehistory strategies fared better than those with opportunistic strategies during an extreme multiyear drought. In general, however, species with life-history traits such as high fecundity, rapid maturation, and small adult size are expected to be more resilient to climatic fluctuations (Filipe, Lawrence, \& Bonada, 2013; Hershkovitz, Dahm, Lorenz, \& Hering, 2015; Williams, Shoo, Isaac, Hoffmann, \& Langham, 2008).

In summary, better knowledge of trait interrelationships derived from phylogeny (Pilière et al., 2016; Poff et al., 2006; Verberk et al., 2013) or life history (Chessman, 2013; Mims \& Olden, 2012, 2013; Verberk et al., 2013) could enhance trait-based study designs and interpretation of results. However, the lack of phylogenetic information for many invertebrate groups could make this difficult.
Accounting for phylogenetic relationships may be a useful addition to trait-based approaches but will not entirely solve the issue of trait intercorrelation. Multivariate trait methods have great potential to help in the assessment of multifaceted responses to environmental drivers (e.g., Boersma et al., 2016), and are being increasingly used (e.g., Kleyer et al., 2012). In particular, the application of multivariate methods to assess vulnerability to climate drivers holds promise (e.g., Conti, Schmidt-Kloiber, Grenouillet, \& Graf, 2014; Foden et al., 2013; Hershkovitz et al., 2015).

\section{5 | META-COMMUNITY PROCESSES INFLUENCE TRAIT-BASED APPROACHES}

We have discussed abiotic environmental filtering as an essential underlying assumption of trait-based approaches. At the same time, we have documented higher rates of failure to confirm expected trait-environment relationships in field studies than that would be expected if this assumption always held. We have also discussed factors that complicate the design and interpretation of trait-based studies, but have not yet considered the environmental contexts under which environmental filtering may structure stream invertebrate communities sufficiently to support such studies. We do this now by exploring the conditions under which alternative models of community assembly apply and how they relate to assumptions underlying trait-based approaches. We focus on the evidence for when environmental filtering, framed as species sorting in the context of meta-communities, is a dominant community assembly process, with the hope of defining conditions under which trait-based study approaches may have to be reconsidered.

A meta-community is defined as '.... set of local communities that are linked by dispersal of multiple potentially interacting species' (Leibold, Economo, \& Peres-Neto, 2010). Table 4 summarizes four common meta-community models and their differences in processes such as dispersal, abiotic filtering, and biotic interactions. The dominant meta-community models are not distinct, but rather represent a continuum of relationships among a suite of factors that together influence community assembly (e.g., dispersion, selection, and speciation: Brown, Sokol, Skelton, \& Tornwall, 2017; Vellend, 2010). Species sorting is one of the many models of meta-community assembly (Leibold et al., 2004; Logue, Mouquet, Peter, \& Hillebrand, 2011; Winegardner, Jones, Ng, Siqueira, \& Cottenie, 2012), and it builds upon the concept of environmental filtering (Soininen, 2014). Under species sorting, it is assumed that species occur in environmental conditions to which they are best suited, and thus there should be strong correlations between environmental variables and species abundances.

Like environmental filtering by abiotic variables, species sorting must predominate to meet the underlying assumptions of trait-based assessment. Although alternative meta-community models are not necessarily mutually exclusive, under conditions where alternative models are as good as species sorting at explaining observed patterns, trait-based assessment of organism responses to abiotic variables may not be fully supported. 
TAB LE 4 Common meta-community models and analytical conventions for differentiating among them

\begin{tabular}{|c|c|c|c|}
\hline Model & Characteristics & Analytical assumptions & References \\
\hline Neutral model & $\begin{array}{l}\text { Communities assembled by random speciation, } \\
\text { dispersal and extinction; assumes that sto- } \\
\text { chastic processes (random events) and envi- } \\
\text { ronmental limitations to dispersal }{ }^{\text {a }} \text { contribute } \\
\text { to determining community composition }\end{array}$ & $\begin{array}{l}\text { Spatial (geographic) factors correlated with commu- } \\
\text { nity compositional patterns }\end{array}$ & $\begin{array}{l}\text { De Bie et } \\
\text { al. (2012), } \\
\text { Cottenie } \\
\text { (2005), Leibold } \\
\text { et al. (2004), } \\
\text { Logue et al. } \\
\text { (2011) }\end{array}$ \\
\hline Patch dynamics & $\begin{array}{l}\text { Habitat patches are considered equivalent and } \\
\text { are occupied according to a balance of disper- } \\
\text { sal ability and competition }\end{array}$ & $\begin{array}{l}\text { Biotic interactions dominate over abiotic factors. } \\
\text { Significant spatial effects with no correlation be- } \\
\text { tween environmental factors } \\
\text { Note: may not be separable from mass effects by } \\
\text { variance structure alone if there is an insufficient } \\
\text { time component to the data set }\end{array}$ & Cottenie (2005) \\
\hline
\end{tabular}

${ }^{a}$ Mainly extrinsic conditions defining dispersal limitations, but these may also interact with intrinsic traits defining dispersal ability.

\section{6 | WHEN DOES SPECIES SORTING APPLY?}

To determine when trait-based vulnerability assessments may be effective, we must understand the environmental contexts within which species sorting applies. A common approach for differentiating among meta-community models is through variance partitioning: strong association between variation in species abundances and abiotic environmental variables is interpreted as supporting species sorting, relationships with both environmental and spatial variables show a role of mass effects along with species sorting, and correlations between species abundances and spatial variables only are interpreted at supporting neutral theory or patch dynamics (Table 4). This process has been criticized, largely because both biotic and abiotic filtering influence communities; and these factors are difficult to separate with field studies (Cadotte \& Tucker, 2017). In addition, spatial autocorrelation of environmental variables, long ecological gradients, or high sampling noise can mask relationships (Tuomisto, Ruokolainen, \& Ruokolainen, 2012). Furthermore, interpreting variance partitions of spatial and environmental variables as attributable to species sorting (niche) and neutral processes is complicated by the effects of dispersal limitation on both, as well as by the spatial configuration of environmental variables (Smith \& Lundholm, 2010). As with environmental filtering, to the extent that biotic interactions contribute to the characterization of niche space, they potentially modify relationships between the abiotic environmental characteristics and species distributions.

We screened the literature for factors determining whether dominance of species sorting can be assumed, recognizing that interpretation of the commonly utilized variance partitioning approach has flaws. While our focus was primarily on trait-based approaches for macroinvertebrates in streams and rivers, we considered literature from a broader range of systems and groups (summarized in Table S3) to understand the scale and nature of factors that influence when environmental filtering and species sorting dominate.

Across organism groups and ecosystem types (96 studies, both terrestrial and aquatic), species sorting or a combination of species sorting and mass effects appear to dominate under most conditions (e.g., Cottenie, 2005), although one review suggested that on average, only $26 \%$ of variance in community composition across community types is explained by measured environmental variables (Soininen, 2014). However, as studies do not comprehensively measure all environmental variables that can explain additional community variation, the degree of support for species sorting might be underestimated (Soininen, 2014), particularly if the range of environmental variation is relatively small. Overall, neutral or patch dynamics models were supported less commonly (fitting about $8 \%$ of communities reviewed by Cottenie, 2005), as was community variation explained by spatial factors (fitting about $11 \%$ of communities reviewed by Soininen, 2016), a pattern often interpreted as supporting a neutral model. 
Species sorting was also reported to predominate in stream macroinvertebrate communities (Table S3), though several researchers reported that its predominance over other meta-community models varied over time and space. A few researchers reported that spatial variables were the strongest determinants of stream macroinvertebrate community assembly, commonly taken as evidence favoring the neutral model. Thompson and Townsend (2006) inferred that both dispersal limitations and local differences in environmental factors contributed to local differences in community structure and suggested that a combination of species sorting and neutral theory may typically apply.

We found that the degree to which species sorting applies varies by ecosystem type, organism group, trophic position, scale, traits under scrutiny, level of disturbance, and the importance of biotic interactions (Table S3), reflecting a mixture of processes from which it is difficult to isolate a single factor (see Cadotte \& Tucker, 2017). From the literature reviewed in Table S3, we summarize some of the key factors that influence the community assembly process, aiming to identify those to consider when designing and implementing traitbased assessments.

Dispersal capacity (Figure 2) is a necessary element of most meta-community models (Leibold et al., 2004; Logue et al., 2011; Tonkin et al., 2017), though they differ in their assumptions about it. For example, patch dynamics assumes species differ in their dispersal abilities, whereas the neutral model assumes they do not. However, the dispersal ability of species is typically difficult to measure and, given the applicability of dispersal to all metacommunity models, this trait is not expected to be particularly useful for differentiating among models, or to better define when trait-based assessments are applicable. Nevertheless, environmental limitations to dispersal may be important to note when developing a study design. In our assessment, the role of dispersal appears to be scale-dependent, with several studies reporting a stronger role for species sorting (i.e., stronger environmental filtering) in headwater streams than in mainstems, though this difference may also depend on location and connectivity (Table S3).

Few studies assessed whether trophic position (e.g., autotroph, primary consumer, secondary consumer) predicted environmental filtering, and their findings were somewhat contradictory (Soininen, 2014, 2016; Table S3). More work is therefore needed to better define any potential role of trophic classification as a factor in the analysis of trait data.

The scale of application may influence the validity of inference from trait-based approaches, with validity likely decreasing with increasing scale. For invertebrate communities in stream ecosystems, species sorting was stronger in smaller streams and over smaller spatial extents and decreased in influence with increasing spatial extent or stream size (Table S3), suggesting that trait-based assessments are likely to be more accurate under the former conditions. At larger scales, the contribution of spatial factors increased. More work is needed to better characterize appropriate scales for the application of trait-based approaches for stream and river invertebrate communities. Should scale be defined in relation to, for example, the scale of habitat patches, the average (or maximum/minimum) dispersal range of species, or the geographic range of species?

As mentioned previously, the extent to which biotic interactions modify community composition, relative to the influence of abiotic environmental variables, complicates the assessment of how abiotic environmental variables control species (or trait state) abundances in a community. Cadotte and Tucker (2017) and Kraft et al. (2015) stressed that several processes may be misinterpreted as species sorting driving community assembly. They suggest that the environment may interact with demographic parameters and competitive exclusion may be a driving force, that is, environmental filtering may act rather indirectly. In addition, environmental factors seem to be less important predictors of community composition in frequently disturbed or very harsh environments where taxa are adapted to extreme disturbance regimes (e.g., de Bello et al., 2013; Datry et al., 2016; Urban, 2004; Table S3).

Overall, most research suggests that species sorting is important for meta-communities in freshwater ecosystems (Grönroos et al., 2013), but variables such as phylogenetic group, spatial scale, biotic interactions, and level of disturbance or environmental harshness moderate the relevance of the paradigm. Thus, these variables will also influence the detection of trait-environment relationships.

\section{7 | CONCLUSIONS}

The appeal of trait-based approaches in the assessment of climate (or other environmental) vulnerabilities arises from their potential insight into mechanisms, providing ecologically based explanations for observed biotic responses to environmental changes and predictions for future responses. Indeed, some of the most robust single trait-environmental variable relationships that we found were for the climate-sensitive variables of temperature and flow. Thus, trait-based studies remain a useful tool contributing to understanding the climate vulnerabilities of stream invertebrate communities, which in particular enable the projections of expected future responses to changing climate-driven environmental variables. However, we show that observed relationships between traits and environmental stressors are often inconsistent with predefined hypotheses derived from current trait-based thinking, particularly related to single-trait relationships. This inconsistency engenders uncertain interpretation of observed trait changes. We used ecological principles and applied meta-community models to outline key elements for refining trait-based hypotheses and study designs and for improving the reliability of associated conclusions, summarized in Table 5. These elements provide direction for the next steps of traits research.

We suggest that intercorrelations among traits and among environmental variables, spatial scale, strength of biotic interactions, and strong habitat disturbance (harshness of the habitat), as well as methods of trait characterization are among the factors that should guide the construction of trait hypotheses and design of trait-based assessments. 
TAB LE 5 Next steps: evidence needed to develop better hypotheses as a basis for trait-based assessments

Recommendations for study element revisions, additional research

Develop analytical approaches to account for intercorrelations among environmental variables and traits

- Develop approaches to predict or account for trait intercorrelations, including taxonomic groups, life-history groups, and empirically defined trait groups

- Define appropriate taxonomic levels to use

- Fill gaps in phylogenetic information for groups that lack it

- Develop approaches for incorporating phylogenetic information and trait associations into data analysis

- Refine characterization of phylogenetic trait linkages

Better characterize appropriate spatial scales for application of traitbased approaches, particularly beyond the scale of small headwater streams

- Improve terminology used to characterize different scales (e.g., local vs. regional)

- Define thresholds of scale relative to dispersal abilities for various taxonomic groups (e.g., according to quantified relative drift occurrence and adult movement patterns), regional variations in salient environmental conditions, and species ranges

Improve approaches for assessing the amount of variation explained by abiotic and biotic environmental variables as a basis for selecting appropriate study areas and designs, including comparisons of trait with taxonomic and phylogenetic diversity

Evaluate disturbance regimes, including frequencies/magnitudes of disturbance, to inform study design, as these regimes can influence the realization of environmental filtering

Develop approaches to incorporate typological (classification) differences among river basins into trait-based approaches

Refine methods for developing trait assignments

- Consider quantitative trait studies to achieve better assignments for categorical traits (e.g., recording occurrences in riffles and pools more rigorously to hone the assignment of erosional, depositional, or intermediate preferences to express the trait of rheophily)

- Consider expansion of trait types to fit a wider array of ecological contexts (e.g., freeze tolerance traits for use in alpine/arctic regions)

- Consider converting categorical traits into continuous variables when possible

- Explore analytical approaches that can consider both categorical and continuous traits

- Consider techniques such as stable isotope analyses to better deal with plasticity in feeding types

As a key element to improve trait-based approaches, several potential methods of accounting for trait intercorrelations should be explored. They include applying multivariate methods to reduce the influence of trait non-independence, using various levels of taxonomic organization to account for phylogenetic determinants of trait linkages, using clustering or other analyses to empirically define trait groups, and using groupings by life history to account for trait correlations.

The legacy of evolutionary history in trait intercorrelations means that we cannot classify all taxa by a single trait and expect uniform responses to a particular environmental factor according to that trait alone. To move forward using traits in a predictive manner, incorporating phylogenetic relatedness may yield better testable hypotheses. A testable hypothesis that would inform this approach would be that traits that are conservative within families (or genera, or orders) determine the distribution of species across ecoregions and stream types, whereas traits that are labile within higher taxa determine local niche-based distribution. Consequently, regional distributions would be better predicted by taxonomy and local distributions by labile traits. However, because phylogeny does not explain all trait intercorrelations, linkages between traits due to mechanistic relationships also must be addressed, as should correlations or interdependencies among environmental variables.

More caution is required in trait-based hypothesis testing at larger (regional) scales or in larger (mainstem) streams or rivers, where other processes become increasingly influential (Table 5). However, further effort is needed to better define the terms we use to characterize scale (e.g., local vs. regional) in this context. Other issues arise when applying trait-based approaches at different scales. For example, there appears to be more trait plasticity over larger geographic areas (e.g., Pilière et al., 2016), and diversity of the species pool at larger spatial scales (beta-diversity) can influence assemblage composition at the local scale (Leibold et al., 2004).

Meta-community level thinking is appropriate to apply to trait-based study design and interpretation, as we are often trying to test for stressor effects and explain response trends at larger (regional) scales (Leibold et al., 2004). This review suggests that for macroinvertebrate communities in stream systems, species sorting is generally the dominant meta-community process, and therefore trait-based assessments should generally be appropriate. However, other meta-community models (e.g., mass effects, neutral processes) may be influential in some contexts (Beisner, PeresNeto, Lindström, Barnett, \& Longhi, 2006; De Bie et al., 2012). The factors that create these contexts are therefore pertinent to traitbased study designs, but not clearly defined, so the challenge is how to account for them. With proper consideration of such issues, trait-based assessment of organismal vulnerability to environmental changes can become a useful tool to conserve threatened populations into the future.

\section{ACKNOWLEDGEMENTS}

The authors would like to thank L. Alexander, G. Pond, and K. Schofield for their review input, which greatly improved this manuscript. The views expressed in this paper represent those of the authors and do not necessarily reflect the views or policies of the U.S. Environmental Protection Agency. The authors acknowledge funding from EPA contracts to Tetra Tech, Inc. \#EP-C-17-031 TO 002 and \#EP-C-12-060 WA 4-01; funding by the German Research Foundation (DFG; grant number: SCHA 1720/18-1); and funding through the 'LimnoSCenES' project (research on social-ecological scenarios for biodiversity and ecosystem service changes in north temperate freshwater ecosystems over the next half century; AD 91/22-1) supported by the network programming and funding 
research on biodiversity and ecosystem services across European countries and territories (BiodivERsA) and the Belmont Forum.

\section{ORCID}

Anna T. Hamilton (iD https://orcid.org/0000-0002-2588-563X

Ralf B. Schäfer (iD https://orcid.org/0000-0003-3510-1701

Karan Kakouei (iD https://orcid.org/0000-0001-8665-6841

\section{REFERENCES}

Allan, J. D., \& Castillo, M. M. (2007). Stream ecology: Structure and function of running waters (2nd ed.). Dordrecht, the Netherlands: Springer.

Bêche, L. A., \& Resh, V. H. (2007). Biological traits of benthic macroinvertebrates in California mediterranean-climate streams: Longterm annual variability and trait diversity patterns. Fundamental and Applied Limnology Archiv für Hydrobiologie, 169, 1-23. https://doi. org/10.1127/1863-9135/2007/0169-0001

Beisner, B. E., Peres-Neto, P. R., Lindström, E. S., Barnett, A., \& Longhi, M. L. (2006). The role of environmental and spatial processes in structuring lake communities from bacteria to fish. Ecology, 87, 29852991. https://doi.org/10.1890/0012-9658(2006)87[2985:TROEA S]2.0.CO;2

Bhowmik, A. K., \& Schäfer, R. B. (2015). Large scale relationship between aquatic insect traits and climate. PLoS ONE, 10(6), e0130025. https:// doi.org/10.1371/journal.pone.0130025

Blanck, A., Tedesco, P. A., \& Lamouroux, N. (2007). Relationships between life-history strategies of European freshwater fish species and their habitat preferences. Freshwater Biology, 52, 843-859. https:// doi.org/10.1111/j.1365-2427.2007.01736.x

Boersma, K. S., Dee, L. E., Miller, S. J., Bogan, M. T., Lytle, D. A., \& Gitelman, A. I. (2016). Linking multidimensional functional diversity to quantitative methods: A graphical hypothesis-evaluation framework. Ecology, 97, 583-593. https://doi.org/10.1890/15-0688

Bonada, N., Dolédec, S., \& Statzner, B. (2007). Taxonomic and biological trait differences of stream macroinvertebrate communities between mediterranean and temperate regions: Implications for future climatic scenarios. Global Change Biology, 13, 1658-1671. https://doi. org/10.1111/j.1365-2486.2007.01375.x

Brown, B. L., Sokol, E. R., Skelton, J., \& Tornwall, B. (2017). Making sense of metacommunities: Dispelling the mythology of a metacommunity typology. Oecologia, 183(3), 643-652. https://doi.org/10.1007/ s00442-016-3792-1

Brown, L. E., Khamis, K., Wilkes, M., Blaen, P., Brittain, J. E., Carrivick, J. L., ... Milner, A. M. (2017). Functional diversity and community assembly of river invertebrates show globally consistent responses to decreasing glacier cover. Nature, Ecology and Evolution, 2, 325-333. https://doi.org/10.1038/s41559-017-0426-x

Cadotte, M. W., Davies, T. J., \& Peres-Neto, P. R. (2017). Why phylogenies do not always predict ecological differences. Ecological Monographs, 87, 535-551. https://doi.org/10.1002/ecm.1267

Cadotte, M. W., \& Tucker, C. M. (2017). Should environmental filtering be abandoned? Trends in Ecology \& Evolution, 32, 429-437. https://doi. org/10.1016/j.tree.2017.03.004

Cañedo-Argüelles, M., Bogan, M. T., Lytle, D. A., \& Prat, N. (2016). Are Chironomidae (Diptera) good indicators of water scarcity? Dryland streams as a case study. Ecological Indicators, 71, 155-162. https:// doi.org/10.1016/j.ecolind.2016.07.002

Chessman, B. C. (2012). Biological traits predict shifts in geographical ranges of freshwater invertebrates during climatic warming and drying. Journal of Biogeography, 39, 957-969. https://doi. org/10.1111/j.1365-2699.2011.02647.x
Chessman, B. C. (2013). Identifying species at risk from climate change: Traits predict the drought vulnerability of freshwater fishes. Biological Conservation, 160, 40-49. https://doi.org/10.1016/j. biocon.2012.12.032

Chessman, B. C. (2015). Relationships between lotic macroinvertebrate traits and responses to extreme drought. Freshwater Biology, 60, 5063. https://doi.org/10.1111/fwb.12466

Chessman, B. C. (2018). Dissolved-oxygen, current and temperature preferences of stream invertebrates estimated from field distributions: Application to assemblage responses to drought. Hydrobiologia, 809(1), 141-153. https://doi.org/10.1007/s10750-017-3455-1

Chevalier, M., Comte, L., Laffaille, P., \& Grenouillet, G. (2018). Interactions between species attributes explain population dynamics in stream fishes under changing climate. Ecosphere, 9(1), e02061. https://doi. org/10.1002/ecs2.2061

Conti, L., Schmidt-Kloiber, A., Grenouillet, G., \& Graf, W. (2014). A traitbased approach to assess the vulnerability of European aquatic insects to climate change. Hydrobiologia, 721(1), 297-315. https://doi. org/10.1007/s10750-013-1690-7

Cottenie, K. (2005). Integrating environmental and spatial processes in ecological community dynamics. Ecology Letters, 8, 1175-1182. https ://doi.org/10.1111/j.1461-0248.2005.00820.x

Cummins, K. W., Spengler, G. L., Ward, G. M., Speaker, R. M., Ovink, R. W., Mahan, D. C., \& Mattingly, R. L. (1980). Processing of confined and naturally entrained leaf litter in a woodland stream ecosystem. Limnology and Oceanography, 25, 952-957. https://doi.org/10.4319/ lo.1980.25.5.0952

Datry, T., Melo, A. S., Moya, N., Zubieta, J., de la Barra, E., \& Oberdorff, T. (2016). Metacommunity patterns across three neotropical catchments with varying environmental harshness. Freshwater Biology, 61, 277-292.

de Bello, F., Šmilauer, P., Diniz-Filho, J. A. F., Carmona, C. P., Lososová, Z., Herben, T., \& Götzenberger, L. (2017). Decoupling phylogenetic and functional diversity to reveal hidden signals in community assembly. Methods in Ecology and Evolution, https://doi. org/10.1111/2041-210X.12735

de Bello, F., Vandewalle, M., Reitalu, T., Lepš, J., Prentice, H. C., Lavorel, S., \& Sykes, M. T. (2013). Evidence for scale- and disturbancedependent trait assembly patterns in dry semi-natural grasslands. Journal of Ecology, 101, 1237-1244. https://doi.org/10.1111/13652745.12139

de Bie, T., De Meester, L., Brendonck, L., Martens, K., Goddeeri, B., Ercken, D., ... Declerck, S. A. J. (2012). Body size and dispersal mode as key traits determining metacommunity structure of aquatic organisms. Ecology Letters, 15, 740-747. https://doi. org/10.1111/j.1461-0248.2012.01794.x

Diniz-Filho, J. A. F., Cianciaruso, M. V., Rangel, T. F., \& Bini, L. M. (2011). Eigenvector estimation of phylogenetic and functional diversity. Functional Ecology, 25, 735-744. https://doi. org/10.1111/j.1365-2435.2011.01836.x

Domisch, S., Araujo, M. B., Bonada, N., Pauls, S. U., Jahnig, S. J., \& Haase, P. (2013). Modelling distribution in European stream macroinvertebrates under future climates. Global Change Biology, 19, 752-762. https://doi.org/10.1111/gcb.12107

Fahy, E. (1975). Quantitative aspects of the distribution of invertebrates in the benthos of a small stream system in western Ireland. Freshwater Biology, 5, 167-182. https://doi.org/10.1111/j.1365-2427.1975. tb00131.x

Filipe, A. F., Lawrence, J. E., \& Bonada, N. (2013). Vulnerability of stream biota to climate change in mediterranean climate regions: A synthesis of ecological responses and conservation challenges. Hydrobiologia, 719, 331-351. https://doi.org/10.1007/s10750-012-1244-4

Foden, W. B., Butchart, S. H. M., Stuart, S. N., Vié, J.-C., Akcakaya, H. R., Angulo, A., ... Mace, G. M. (2013). Identifying the world's most climate change vulnerable species: A systematic trait-based assessment of 
all birds, amphibians, and corals. PLoS ONE, 6, e65427. https://doi. org/10.1371/journal.pone.0065427

Giller, P. S., \& Malmqvist, B. (1998). The biology of streams and rivers. New York, NY: Oxford University Press.

Goudie, A. S. (2018). Human impact on the natural environment. West Sussex, UK: Wiley-Blackwell. ISBN 978-1-119-40373-9.

Griswold, M. W., Berzinis, R. W., Crisman, T. L., \& Golladay, S. W. (2008). Impacts of climatic stability on the structural and functional aspects of macroinvertebrate communities after severe drought. Freshwater Biology, 53, 2465-2483. https://doi.org/10.1111/j.13652427.2008.02067.x

Grönroos, M., Heino, J., Siqueira, T., Landeiro, V. L., Kotanen, J., \& Bini, L. M. (2013). Metacommunity structuring in stream networks: Roles of dispersal mode, distance type, and regional environmental context. Ecology and Evolution, 3, 4473-4487. https://doi.org/10.1002/ece3.834

Guénard, G., Legendre, P., \& Peres-Neto, P. (2013). Phylogenetic eigenvector maps: A framework to model and predict species traits. Methods in Ecology and Evolution, 4, 1120-1131. https://doi.org/10.1111/ 2041-210X.12111

Hamilton, A. T., Stamp, J. D., \& Bierwagen, B. G. (2010). Vulnerability of biological metrics and multi-metric indices to effects of climate change. Journal of the North American Benthological Society, 29(4), 1379-1396. https://doi.org/10.1899/10-053.1

Hawkins, C. P., Murphy, M. L., \& Anderson, N. H. (1982). Effects of canopy, substrate composition, and gradient on the structure of macroinvertebrate communities in Cascade Range streams of Oregon. Ecology, 63, 1840-1856. https://doi.org/10.2307/1940125

Herbst, D. B., Cooper, S. D., Medhurst, R. B., Wiseman, S. W., \& Hunsaker, C. T. (2018). A comparison of the taxonomic and trait structure of macroinvertebrate communities between the riffles and pools of montane headwater streams. Hydrobiologia, 820, 115-133. https:// doi.org/10.1007/s10750-018-3646-4

Hering, D., Schmidt-Kloiber, A., Murphy, J., Lücke, S., Zamora-Muñoz, C., López-Rodríguez, M. J., ... Graf, W. (2009). Potential impact of climate change on aquatic insects: A sensitivity analysis for European caddisflies (Trichoptera) based on distribution patterns and ecological preferences. Aquatic Sciences, 71, 3-14, 1015-1621/09/010003-12. https://doi.org/10.1007/s00027-009-9159-5

Hershkovitz, Y., Dahm, V., Lorenz, A. W., \& Hering, D. (2015). A multi-trait approach for the identification and protection of European freshwater species that are potentially vulnerable to the impacts of climate change. Ecological Indicators, 50, 150-160. https://doi.org/10.1016/j. ecolind.2014.10.023

Hynes, H. B. N. (1970). The ecology of running waters. Toronto, Canada: University of Toronto Press, 555 pp. ISBN 10: 1930665334. ISBN-13: 978-1930665330.

Kakouei, K., Kiesel, J., Domisch, S., Irving, K. S., Jähnig, S. C., \& Kail, J. (2018). Projected effects of climate-change-induced flow alterations on stream macroinvertebrate abundances. Ecology and Evolution, 8, 3393-3409. https://doi.org/10.1002/ece3.3907

Kleyer, M., Dray, S., Bello, F., Lepš, J., Pakeman, R. J., Strauss, B., ... Lavorel, S. (2012). Assessing species and community functional responses to environmental gradients: Which multivariate methods? Journal of Vegetation Science, 23, 805-821. https://doi. org/10.1111/j.1654-1103.2012.01402.x

Kraft, N. J. B., Adler, P. B., Godoy, O., James, E. C., Fuller, S., \& Levine, J. M. (2015). Community assembly, coexistence and the environmental filtering metaphor. Functional Ecology, 29, 592-599. https://doi. org/10.1111/1365-2435.12345

Lange, K., Townsend, C. R., \& Matthaei, C. D. (2014). Can biological traits of stream invertebrates help disentangle the effects of multiple stressors in an agricultural catchment? Freshwater Biology, 59, 2431-2446. https://doi.org/10.1111/fwb.12437

Lawrence, J. E., Lunde, K. B., Mazor, R. D., Bêche, L. A., McElravy, E. P., \& Resh, V. H. (2010). Long-term macroinvertebrate responses to climate change: Implications for biological assessment in Mediterranean-climate streams. Journal of the North American Benthological Society, 29(4), 1424-1440. https://doi. org/10.1899/09-178.1

Leibold, M. A., Economo, E. P., \& Peres-Neto, P. (2010). Metacommunity phylogenetics: Separating the roles of environmental filters and historical biogeography. Ecology Letters, 13(10), 1290-1299. https://doi. org/10.1111/j.1461-0248.2010.01523.x

Leibold, M. A., Holyoak, M., Mouquet, N., Amarasekare, P., Chase, J. M., Hoopes, M. F., ... Gonzalez, A. (2004). The metacommunity concept: A framework for multi-scale community ecology. Ecology Letters, 7, 601-613. https://doi.org/10.1111/j.1461-0248.2004.00608.x

Logue, J. B., Mouquet, N., Peter, H., \& Hillebrand, H.; The Metacommunity Working Group. (2011). Empirical approaches to metacommunities: A review and comparison with theory. Trends in Ecology \& Evolution, 26, 482-491. https://doi.org/10.1016/j.tree.2011.04.009

Malaj, E., Guénard, G., Schäfer, R. B., \& von der Ohe, P. C. (2016). Evolutionary patterns and physicochemical properties explain macroinvertebrate sensitivity to heavy metals. Ecological Applications, 26, 1249-1259. https://doi.org/10.1890/15-0346

Mbaka, J. G., Szöcs, E., \& Schäfer, R. B. (2015). Meta-analysis on the responses of traits of different taxonomic groups to global and local stressors. Acta Oecologica, 69, 65-70. https://doi.org/10.1016/ j.actao.2015.09.002

McCafferty, W. P. (1998). Aquatic entomology: The fishermen's and ecologists' illustrated guide to insects and their relatives. Boston, MA: Jones and Bartlett.

McGill, B. J., Enquist, B., Weiher, E., \& Westoby, M. (2006). Rebuilding ecology from functional traits. Trends in Ecology \& Evolution, 21, 178185. https://doi.org/10.1016/j.tree.2006.02.002

McManamay, R. A., \& Frimpong, E. A. (2015). Hydrologic filtering of fish life-history strategies across the United States: Implications for stream flow alteration. Ecological Applications, 25, 243-263. https:// doi.org/10.1890/14-0247.1

Merritt, R. W., Cummins, K. W., \& Berg, M. B. (Eds.). (2008). An introduction to the aquatic insects of North America (4th ed.). Dubuque, IA: Kendall/Hunt Publishing Company.

Millennium Ecosystem Assessment (MEA). (2005). Ecosystems and human well-being: Synthesis. Washington, DC: Island Press.

Mims, M. C., \& Olden, J. D. (2012). Life-history theory predicts fish assemblage response to hydrologic regimes. Ecology, 93, 35-45. https ://doi.org/10.1890/11-0370.1

Mims, M. C., \& Olden, J. D. (2013). Fish assemblages respond to altered flow regimes via ecological filtering of life-history strategies. Freshwater Biology, 58, 50-62. https://doi.org/10.1111/fwb.12037

Olden, J. D., \& Kennard, M. J. (2010). Intercontinental comparison of fish life-history strategies along a gradient of hydrologic variability. In K. B. Gido, \& D. A. Jackson (Eds.), Community ecology of stream fishes: Concepts, approaches, and techniques (pp. 83-107). Bethesda, MD: American Fisheries Society.

Ortega-Mayagoitia, E., Hernandez-Martinez, O., \& Ciros-Perez, J. (2018). Phenotypic plasticity of life-history traits of a calanoid copepod in a tropical lake: Is the magnitude of thermal plasticity related to thermal variability? PLoS ONE, 13(4), e0196496. https://doi.org/10.1371/ journal.pone.0196496

Pilière, A. F. H., Verberk, W. C. E. P., Gräwe, M., Breure, A. M., Dyer, S. D., Posthuma, L., ... Schipper, A. M. (2016). On the importance of trait interrelationships for understanding environmental responses of stream macroinvertebrates. Freshwater Biology, 61, 181-194. https ://doi.org/10.1111/fwb.12690

Pillar, V. D., \& Duarte, L. D. S. (2010). A framework for metacommunity analysis of phylogenetic structure. Ecology Letters, 13, 587-596. https://doi.org/10.1111/j.1461-0248.2010.01456.x

Poff, N. L. (1997). Landscape filters and species traits: Towards mechanistic understanding and prediction in stream ecology. Journal of 
the North American Benthological Society, 16, 391-409. https://doi. org/10.2307/1468026

Poff, N. L., Olden, J. D., Vieira, N. K. M., Finn, D. S., Simmons, M. P., \& Kondratieff, B. C. (2006). Functional trait niches of North American lotic insects: Trait-based ecological applications in light of phylogenetic relationships. Journal of the North American Benthological Society, 25, 730-755. https://doi.org/10.1899/0887-3593(2006)025 [0730:FTNONA]2.0.CO;2

Poff, N. L., Pyne, M. I., Bledsoe, B. P., Cuhaciyan, C. C., \& Carlisle, D. M. (2010). Developing linkages between species traits and multiscaled environmental variation to explore vulnerability of stream benthic communities to climate change. Journal of the North American Benthological Society, 29(4), 1441-1458. https://doi. org/10.1899/10-030.1

Pyne, M. I., \& Poff, N. L. (2017). Vulnerability of stream community composition and function to projected thermal warming and hydrologic change across ecoregions in the western United States. Global Change Biology, 23, 77-93. https://doi.org/10.1111/gcb. 13437

Resh, V. H., Brown, A. V., Covich, A. P., Gurtz, M. E., Li, H. W., Minshall, G. W., ... Wissmar, R. C. (1988). The role of disturbance in stream ecology. Journal of the North American Benthological Society, 7, 433-455. https://doi.org/10.2307/1467300

Scharbert, A., \& Borcherding, J. (2013). Relationships of hydrology and life-history strategies on the spatio-temporal habitat utilisation of fish in European temperate river floodplains. Ecological Indicators, 29, 348-360. https://doi.org/10.1016/j.ecolind.2013.01.009

Schmidt-Kloiber, A., \& Hering, D. (2015). www.freshwaterecology.info - An online tool that unifies, standardises and codifies more than 20,000 European freshwater organisms and their ecological preferences. Ecological Indicators, 53, 271-282. https://doi.org/10.1016/ j.ecolind.2015.02.007

Serra, S. R. Q., Cobo, F., Graça, M. A. S., Dolédec, S., \& Feio, M. J. (2016). Synthesising the trait information of European Chironomidae (Insecta: Diptera): Towards a new database. Ecological Indicators, 61(2), 282-292. https://doi.org/10.1016/j.ecolind.2015.09.028

Smith, T. W., \& Lundholm, J. T. (2010). Variation partitioning as a tool to distinguish between niche and neutral processes. Ecography, 33, 648-655. https://doi.org/10.1111/j.1600-0587.2009.06105.x

Soininen, J. (2014). A quantitative analysis of species sorting across organisms and ecosystems. Ecology, 95, 3284-3292. https://doi. org/10.1890/13-2228.1

Soininen, J. (2016). Spatial structure in ecological communities - A quantitative analysis. Oikos, 125, 160-166. https://doi.org/10.1111/ oik.02241

Stamp, J. D., Hamilton, A., Zheng, L., \& Bierwagen, B. (2010). Use of thermal preference metrics to examine state biomonitoring data for climate change effects. Journal of the North American Benthological Society, 29, 1410-1423. https://doi.org/10.1899/10-003.1

Thompson, R., \& Townsend, C. (2006). A truce with neutral theory: Local deterministic factors, species traits and dispersal limitation together determine patterns of diversity in stream invertebrates. Journal of Animal Ecology, 75, 476-484. https://doi.org/10.1111/ j.1365-2656.2006.01068.x

Tonkin, J. D., Shah, R. D. T., Shah, D. N., Hoppeler, F., Jähnig, S. C., \& Pauls, S. U. (2017). Metacommunity structuring in Himalayan streams over large elevational gradients: The role of dispersal routes and niche characteristics. Journal of Biogeography, 44, 62-74. https:// doi.org/10.1111/jbi.12895

Tonn, W. M. (1990). Climate change and fish communities: A conceptual framework. Transactions of the American Fisheries Society, 119, 337352. https://doi.org/10.1577/1548-8659(1990)119<0337:CCAFC A $>2.3 . \mathrm{CO} ; 2$

Townsend, C. R., Hildrew, A., \& Francis, J. (1983). Community structure in some southern English streams: The influence of physicochemical factors. Freshwater Biology, 13, 521-544. https:// doi.org/10.1111/j.1365-2427.1983.tb00011.x

Tucker, C., Cadotte, M. W., Carvalho, S. B., Davies, T. J., Ferrier, S., Fritz, S. A., ... Mazel, F. (2017). A guide to phylogenetic metrics for conservation, community ecology and macroecology. Biological Reviews, 92, 698-715. https://doi.org/10.1111/brv.12252

Tucker, C., Davies, T. J., Cadotte, M. W., \& Pearse, W. D. (2018). On the relationship between phylogenetic diversity and trait diversity. Ecology, 99(6), 1473-1479. https://doi.org/10.1002/ecy.2349

Tuomisto, H., Ruokolainen, L., \& Ruokolainen, K. (2012). Modelling niche and neutral dynamics: On the ecological interpretation of variation partitioning results. Ecography, 35, 961-971. https://doi. org/10.1111/j.1600-0587.2012.07339.x

Urban, M. C. (2004). Disturbance heterogeneity determines freshwater metacommunity structure. Ecology, 85(11), 2971-2978.

Usseglio-Polatera, P., Bournaud, M., Richoux, P., \& Tachet, H. (2000). Biological and ecological traits of benthic freshwater macroinvertebrates: Relationships and definitions of groups with similar traits. Freshwater Biology,43,175-205.https://doi.org/10.1046/j.1365-2427.2000.00535.x

Usseglio-Polatera, P., Richoux, P., Bournaud, M., \& Tachet, H. (2001). A functional classification of benthic macroinvertebrates based on biological and ecological traits: Application to river condition assessment and stream management. Archiv Für Hydrobiologie, 139(Supplement), 53-83.

Usseglio-Polatera, P., \& Tachet, H. (1994). Theoretical habitat templets, species traits, and species richness: Plecoptera and Ephemeroptera in the Upper Rhône River and its floodplain. Freshwater Biology, 31(3), 357-375. https://doi.org/10.1111/j.1365-2427.1994.tb017 49. $x$

Vellend, M. (2010). Conceptual synthesis in community ecology. The Quarterly Review of Biology, 85(2), 183-206. https://doi.org/10.1086/ 652373

Verberk, W. C. E. P., Siepel, H., \& Esselink, H. (2008). Life-history strategies in freshwater macroinvertebrates. Freshwater Biology, 53, 17221738. https://doi.org/10.1111/j.1365-2427.2008.02035.x

Verberk, W. C. E. P., van Noordwijk, C. G. E., \& Hildrew, G. (2013). Delivering on a promise: Integrating species traits to transform descriptive community ecology into a predictive science. Freshwater Science, 32, 531-547. https://doi.org/10.1899/12-092.1

Vörösmarty, C. J., McIntyre, P. B., Gessner, M. O., Dudgeon, D., Prusevich, A., Green, P., ... Davies, P. M. (2010). Global threats to human water security and river biodiversity. Nature, 467, 555-561. https://doi. org/10.1038/nature09440

Walters, A. W. (2011). Resistance of aquatic insects to a low-flow disturbance: Exploring a trait-based approach. Journal of the North American Benthological Society, 30, 346-356. https://doi. org/10.1899/10-041.1

Ward, J. V. (1992). Aquatic insect ecology, I. Biology and habitat. New York, NY: Wiley.

Webb, C. O., Ackerly, D. D., McPeek, M. A., \& Donoghue, M. J. (2002). Phylogenies and community ecology. Annual Review of Ecology and Systematics, 33, 475-505. https://doi.org/10.1146/annurev.ecols ys.33.010802.150448

Webb, C. T., Hoeting, J. A., Ames, G. M., Pyne, M. I., \& Poff, N. L. (2010). A structured and dynamic framework to advance trait-based theory and prediction in ecology. Ecology Letters, 13, 267-283. https://doi. org/10.1111/j.1461-0248.2010.01444.x

Williams, S. E., Shoo, L. P., Isaac, J. L., Hoffmann, A. A., \& Langham, G. (2008). Towards an integrated framework for assessing the vulnerability of species to climate change. PLoS Biology, 6, 2621-2626. https ://doi.org/10.1371/journal.pbio.0060325

Winegardner, A. K., Jones, B. K., Ng, I. S. Y., Siqueira, T., \& Cottenie, K. (2012). The terminology of metacommunity ecology. Trends in Ecology \& Evolution, 27, 253-254. https://doi.org/10.1016/j. tree.2012.01.007 
Winemiller, K. O., Fitzgerald, D. B., Bower, L. M., \& Pianka, E. R. (2015). Functional traits, convergent evolution, and periodic tables of niches. Ecology Letters, 18, 737-751. https://doi.org/10.1111/ele.12462

Winemiller, K. O., \& Rose, K. A. (1992). Patterns of life-history diversification in North American fishes: Implications for population regulation. Canadian Journal of Fisheries and Aquatic Sciences, 49, 2196-2218. https://doi.org/10.1139/f92-242

Woodward, G., Bonada, N., Feeley, H. B., \& Giller, P. S. (2015). Resilience of a stream community to extreme climatic events and long-term recovery from a catastrophic flood. Freshwater Biology, 60, 2497-2510. https://doi.org/10.1111/fwb.12592

Wuebbles, D. J., Fahey, D. W., Hibbard, K.A., Dokken, D. J., Stewart, B. C., \& Maycock, T. K., (Eds.), (2017). Climate science special report: Fourth National Climate Assessment (Vol. I). Washington, DC: U.S. Global Change Research Program, 470 pp. https://doi.org/10.7930/ J0J964J6

Yuan, L. L. (2006). Estimation and application of macroinvertebrate tolerance values. Washington, DC: U.S. Environmental Protection
Agency, National Center for Environmental Assessment, 89 pp. EPA/600/P-04/116F.

\section{SUPPORTING INFORMATION}

Additional supporting information may be found online in the Supporting Information section.

How to cite this article: Hamilton AT, Schäfer RB, Pyne MI, et al. Limitations of trait-based approaches for stressor assessment: The case of freshwater invertebrates and climate drivers. Glob Change Biol. 2019;00:1-16. https://doi. org/10.1111/gcb.14846 